\title{
Shufeng Jiedu capsules for treating acute exacerbations of chronic obstructive pulmonary disease: a systematic review and meta-analysis
}

Ru-yu Xia ${ }^{1}$, Xiao-yang Hu' ${ }^{2}$, Yu-tong Fei ${ }^{1}$, Merlin Willcox ${ }^{2}$ Ling-zi Wen ${ }^{1}$, Ming-kun Yu ${ }^{1}$, Li-shan Zhang ${ }^{3}$, Meng-yuan Dai ${ }^{4}$, Guang-he Fei ${ }^{4}$, Mike Thomas ${ }^{2}$, Nick Francis ${ }^{2}$, Tom Wilkinson ${ }^{5}$, Michael Moore ${ }^{2}$ and Jian-ping Liu ${ }^{1,6^{*}}$

\begin{abstract}
Background: Chinese herbal medicine is widely used in combination with usual care for acute exacerbations of chronic obstructive pulmonary disease (AECOPD) in China. Chinese patent medicine Shufeng Jiedu (SFJD) capsules is widely used for respiratory infectious diseases. This review aims to evaluate effectiveness and safety of SFJD for AECOPD.

Methods: A systematic review of randomised controlled trials (RCTs) in patients with AECOPD, who received SFJD as a single intervention or as add-on treatment to usual care. PubMed, the Cochrane Library, EMBASE, Scopus, Web of Science and four Chinese databases were searched from inception to April 2019. Two authors screened trials, extracted data, and assessed risk of bias, independently. Meta-analysis was performed using RevMan 5.3 software. We performed subgroup analyses and sensitivity analyses according to the predefined protocol. Quality of evidence was assessed using GRADE.

Results: Thirteen RCTs (1036 patients, with 936 inpatients) were included, all compared SFJD in combination with usual care (including antibiotics) to usual care alone. The mean age of participants ranged from 52 to 67 years, with approximately $60 \%$ male. Due to lack of blinding and other factors, all trials were of high risk of bias. SFJD was associated with a significant reduction in treatment failure, from 20.1 to $8.3 \%$ (11 trials; 815 patients; relative risk $0.43,95 \%$ confidence interval [CI 0.30 to 0.62 ), and duration of hospital stay ( 2 trials; 79 patients; mean difference 4.32 days, $95 \% \mathrm{Cl}-5.89$ to -2.75 days). No significant difference in adverse events was found between SFJD and control groups.

(Continued on next page)
\end{abstract}

\footnotetext{
* Correspondence: jianping_l@hotmail.com; liujp@bucm.edu.cn

${ }^{1}$ Centre for Evidence-Based Chinese Medicine, Beijing University of Chinese

Medicine, No. 11 North Sanhuan East Road, Chaoyang District, Beijing

100029, China

${ }^{6}$ Institute of Integrated Traditional Chinese Medicine and Western Medicine,

Guangzhou Medical University, Guangzhou 510120, China

Full list of author information is available at the end of the article
}

(c) The Author(s). 2020 Open Access This article is licensed under a Creative Commons Attribution 4.0 International License, which permits use, sharing, adaptation, distribution and reproduction in any medium or format, as long as you give appropriate credit to the original author(s) and the source, provide a link to the Creative Commons licence, and indicate if changes were made. The images or other third party material in this article are included in the article's Creative Commons licence, unless indicated otherwise in a credit line to the material. If material is not included in the article's Creative Commons licence and your intended use is not permitted by statutory regulation or exceeds the permitted use, you will need to obtain permission directly from the copyright holder. To view a copy of this licence, visit http://creativecommons.org/licenses/by/4.0/ The Creative Commons Public Domain Dedication waiver (http://creativecommons.org/publicdomain/zero/1.0/) applies to the data made available in this article, unless otherwise stated in a credit line to the data. 
(Continued from previous page)

Conclusion: Low certainty evidence suggests SFJD may bring additional benefit in reducing treatment failure, shorten hospital stay, and improving symptoms. Further large, high quality RCTs are needed to confirm its benefit and safety.

Trial registration: PROSPERO CRD42019133682.

Keywords: COPD, Exacerbation, Shufeng Jiedu, Systematic review, Meta-analysis, Chinese herbal medicine, Randomised controlled trial

\section{Background}

Chronic obstructive pulmonary disease (COPD) is one of most common causes of impaired health [1]. In China, around 99.9 million people, $8.6 \%$ of the Chinese population aged 20 years or older, live with COPD [2]. In the UK there is an estimation of 3 million COPD patients, among whom 1.2 million have been diagnosed, costing the National Health Service over 800 million pounds per year $[3,4]$. Acute exacerbations of chronic obstructive pulmonary disease (AECOPD) are defined as an acute worsening of respiratory symptoms that require additional therapy [5-9]. Patients with COPD on average experience 0.5-3.5 acute exacerbations per year [10]. Acute exacerbations lead to a decline in lung function and quality of life, increased need for hospitalisation, and are associated with increased risk of death $[11,12]$, therefore account for the greatest proportion of the total COPD burden on healthcare system $[13,14]$.

AECOPD can be triggered by several factors, with the most common causes being respiratory infections caused by bacteria or viruses (which may coexist) and noninfectious environmental factors such as pollution or allergens. Severe exacerbations may require hospitalisation or visits to the emergency department and may be associated with acute respiratory failure. Bronchodilators are commonly prescribed in combination with systemic corticosteroids, antibiotics and other respiratory support in the treatment of AECOPD. These therapies are supported by evidence from randomised controlled trials and are recommended by guidelines [9, 15]. However, these interventions are known to cause a variety of adverse effects, including, dry mouth, tremor, hyperglycaemia, diarrhoea, and antibiotic resistance [16-18].

Shufeng Jiedu (SFJD) capsule is an oral patent Chinese herbal medicine widely used in China for the treatment of respiratory infections (a list of all ingredients of Shufeng Jiedu is available in Additional file 1: Table 1). Published systematic reviews [19-26] have evaluated the effects of many traditional Chinese herbal medicine decoctions and injections on clinical outcomes including symptoms, pulmonary function and quality of life in patients with AECOPD. However, there is no published systematic review evaluating the effectiveness and safety of SFJD as a treatment for AECOPD. In light of the recently published randomised controlled trials (RCTs) on SFJD, we aimed to evaluate the effectiveness and safety of SFJD for AECOPD by conducting a systematic review and meta-analysis where appropriate.

\section{Methods}

This systematic review is reported in accordance with the PRISMA statement [27] and has been prospectively registered on PROSPERO [28].

\section{Eligibility criteria}

We included RCTs of SFJD as a single intervention or in combination with usual treatment (e.g. bronchodilators and antibiotics), compared to usual treatment alone, placebo, waiting list or no treatment. Participants were patients with a clinical diagnosis of AECOPD. The primary outcome was treatment failure as observed at the end of treatment. Treatment failure was defined as no resolution or deterioration of symptoms after trial medication of any duration, or death (when explicitly stated, due to exacerbation) or additional course of antibiotics or another medication for the treatment of AECOPD [17].

Secondary outcomes included all-cause mortality, duration of hospital stay (for inpatients), admission to an intensive care unit (ICU), re-exacerbations within two to 6 weeks of index exacerbation (inpatient or outpatient treatment, rates or time to event), time to resolution of clinical symptoms (e.g. dyspnoea, cough, wheezing, sputum, or fever), arterial blood gas measurements at the end of treatment (partial pressure of oxygen in arterial blood ( $\mathrm{PaO} 2)$ and partial pressure of carbon dioxide in arterial blood (PaCO2)), lung function - forced expiratory volume in $1 \mathrm{~s}$ (FEV1) / forced vital capacity (FVC) ratio, markers of infection (white blood cell count, proportion of neutrophils, C-reactive protein, procalcitonin), antibiotic usage (change of modes of administration of antibiotics, change of antibiotic, duration of antibiotic treatment or number of patients who used antibiotics), health related quality of life and adverse events (unintended symptoms or signs, e.g. abnormal liver/ kidney function or ECG, or disease).

\section{Information sources}

We searched English databases PubMed, the Cochrane Library, EMBASE, Scopus, Web of Science, and Chinese 
databases China National Knowledge Infrastructure (CNKI), Chinese Scientific Journal Database (VIP), SinoMed and Wanfang from their inception to April 2019. The PubMed search used the following words in Title/Abstract field: "Shufengjiedu" or "Shu Feng Jie Du" or "Shu-Feng-Jie-Du" or "Shufeng Jiedu" or "ShufengJiedu". We conducted searches of ClinicalTrials.gov (www.ClinicalTrials.gov) and Chinese Clinical Trial Registry (http://www.chictr.org.cn/index.aspx). We also searched reference lists of included studies and existing systematic reviews.

\section{Literature screening, data extraction and quality assessment}

After removing duplicates, paired trained reviewers independently screened titles and abstracts of all potential studies identified from searches. When there were uncertainties, insufficient information, or in cases of disagreement, we obtained full texts of the articles, then determined eligibility by screening the full texts. Reasons for excluding articles at full text screening stage were recorded.

After identifying eligible studies, paired reviewers independently extracted trial characteristics on sample size, setting and source of funding, characteristics of the trial population on age and sex, information about the illness including diagnostic criteria and illness duration, trial inclusion and exclusion criteria, details of interventions in all trial arms, outcome measures, and risk of bias domains from included trials using standardised pilot tested forms with detailed instructions.

Quality of the eligible studies was assessed by two reviewers using a modified Cochrane Risk of Bias Tool with four response options: "probably no", "no", "probably yes", and "yes" [29, 30]. We also used the five GRADE (Grading of Recommendations Assessment, Development and Evaluation) considerations (risk of bias, directness, precision, consistency, and the possibility of publication bias) to assess methodological confidence of a body of evidence for prespecified outcomes [31]. For all phases of the review, we dealt with discrepancies through discussion or adjudication by a third reviewer when necessary. Chance-corrected Kappa [32] was calculated as a measure of agreement among reviewers' judgements.

\section{Data synthesis and analysis}

We conducted analyses using risk ratio (RR) with 95\% confidence intervals (CI) for dichotomous data; mean difference (MD) or standard mean difference (SMD) with $95 \%$ CI for continuous data. We pooled data quantitatively through Review Manager (version 5.3) when the trials had admissible clinical homogeneity and statistical heterogeneity as measured by Cochrane $X^{2}$ test and
$I^{2}$ statistic, or where heterogeneity could be explained by predefined subgroup analysis [29, 33]. Otherwise only qualitative description of the data was presented. A fixed-effects model was considered when $I^{2}$ was $<30 \%$, otherwise, a random-effects model was utilised.

To explain heterogeneity, we conducted subgroup analyses predefined via AECOPD severity (outpatients, inpatients and patients admitted to the ICU), treatment duration ( $\leq 7$ days or $>7$ days), mode of administration of antibiotics, and complications. We conducted sensitivity analyses to challenge the robustness of the results when there were clinically meaningful differences in primary outcomes considering: multi-centre versus single centre, clear versus unclear randomisation concealment, placebo used versus not used, reported loss-to-follow-up versus not reported, assumed worst plausible case results for patients in intervention groups with missing data [34].

We generated a funnel plot through Review Manager (version 5.3), and performed Begg's test and Egger's test through $\mathrm{R}$ (version 3.6.1) when ten or more studies were presented in a meta-analysis to examine publication bias.

\section{Results}

The literature search identified 688 unique citations, among which 20 were judged potentially eligible at title and abstract screening. Further screening of full text identified 13 RCTs involving 1036 patients, of which 936 were hospitalised patients (Fig. 1). Chance-corrected Kappa for agreements is 0.95 for title and abstract screening, 0.77 for full text screening, and 0.91 for assessment of risk of bias of included studies.

\section{Trial characteristics}

All studies were single centre trials and conducted in China, and none reported sources of funding or conflicts of interest. Sample size ranged from 40 to 130, more than half of the participants were male in each trial, and the mean age ranged from 52 to 67 years (Table 1) [3547]. Patients in intervention groups all received SFJD along with antibiotics and symptomatic treatments (such as bronchodilators and supplemental oxygen), while the comparison groups all received antibiotics and symptomatic treatments without SFJD. The duration of treatment ranged from 6 [47] to 14 days [41, 46]. In all included trials, the dose of SFJD was 4 capsules per time, 3 times daily.

\section{Risk of Bias assessment}

Three trials reported clear randomisation concealment [40, 41, 47]. Placebo was not used in any of the studies, so there was no blinding of patients or clinicians. Loss to follow-up was rarely reported; two trials had more than $5 \%$ attrition $[35,36]$ (Table 2). 


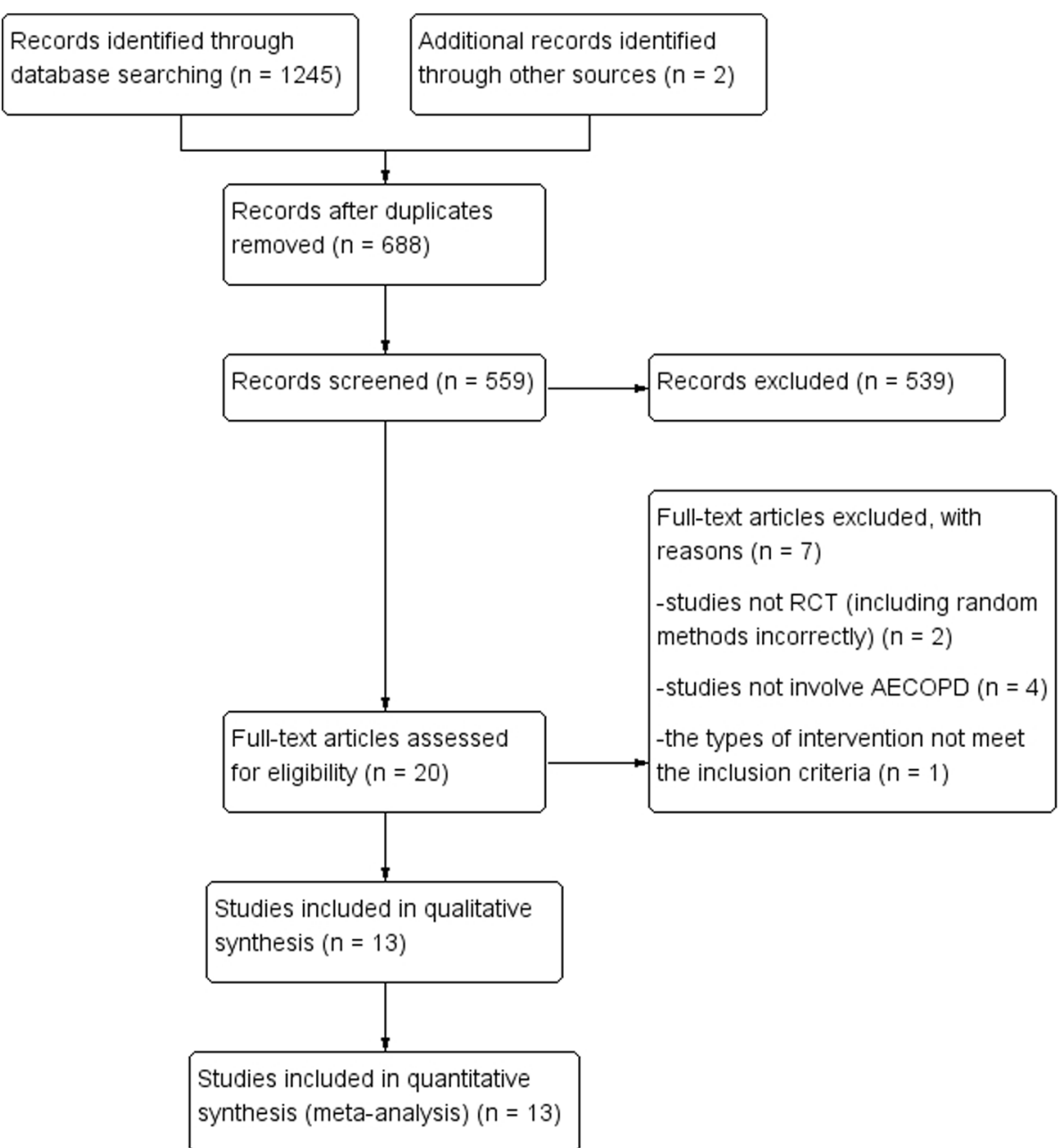

Fig. 1 Flow diagram. RCT: randomised controlled trial; AECOPD: acute exacerbations of chronic obstructive pulmonary disease

\section{Outcomes}

No trial reported information about all-cause mortality, re-exacerbation or antibiotic dosage.

\section{Treatment failure}

Eleven trials [36-41, 43-47] addressed treatment failure (details of treatment failure criteria are presented in Additional file 1: Table 2), with 35 of 422 (8.3\%) patients experienced treatment failure in the SFJD group compared to 79 of $393(20.1 \%)$ patients in the control group (RR $0.43,95 \%$ CI 0.30 to $0.62 ; \mathrm{I}^{2}=0 \%$; low certainty) (Fig. 2). Certainty in evidence was rated as low due to the lack of blinding and because a small number of events (Table 3). No subgroup analyses or sensitivity analyses materially changed the results (Additional file 1: Table 3, Figures 1, 2, 3, 4 and 5). The results of all subgroup analyses and sensitivity analyses were listed in the Additional file 1: Table 3. We were not able to detect publication bias for treatment failure using funnel plots (Fig. 3), Begg's test $(P=0.94)$, and Egger's test $(P=0.95)$.

\section{Duration of hospital stay}

Two trials [38, 44] (79 patients) demonstrated a significant reduction in the length of hospitalisation (MD 4.32 days; -5.89 to -2.75 days; $I^{2}=65 \%$; low certainty) in SFJD group (Additional file 1: Figure 6).

\section{ICU admission}

Only one trial [36] (120 patients) provided data on admission to an ICU for mechanical ventilation among patients not in an ICU at the time of enrolment. Six of 60 patients in the SFJD group and seven of 60 patients in the control group were admitted to an ICU respectively.

\section{Time to resolution of clinical symptoms}

Two trials [43, 47] (79 patients) evaluated time to resolution of fever. The pooled results showed no significant 
Table 1 Characteristics of included trials

\begin{tabular}{|c|c|c|c|c|c|c|c|c|c|c|c|}
\hline \multirow{2}{*}{$\begin{array}{l}\text { Study } \\
\text { ID }\end{array}$} & \multirow{2}{*}{$\begin{array}{l}\text { Outpatient } \\
\text { /inpatient }\end{array}$} & \multirow{2}{*}{$\begin{array}{l}\text { Exacerbation } \\
\text { occur within } \\
\mathrm{n} \text { hours of } \\
\text { study } \\
\text { enrolment }\end{array}$} & \multirow[t]{2}{*}{ Funding } & \multirow{2}{*}{$\begin{array}{l}\text { Sample } \\
\text { size }\end{array}$} & \multirow{2}{*}{$\begin{array}{l}\text { Average } \\
\text { age } \\
\text { (year) }\end{array}$} & \multirow{2}{*}{$\begin{array}{l}\text { Male } \\
(\%)\end{array}$} & \multicolumn{2}{|l|}{ Treatment } & \multirow{2}{*}{$\begin{array}{l}\text { Use of } \\
\text { placebo }\end{array}$} & \multirow{2}{*}{$\begin{array}{l}\text { Treatment } \\
\text { duration } \\
\text { (days) }\end{array}$} & \multirow{2}{*}{$\begin{array}{l}\text { Outcome } \\
\text { measurements } \\
\text { b }\end{array}$} \\
\hline & & & & & & & $\begin{array}{l}\text { Add-on } \\
\text { treatment in } \\
\text { experimental } \\
\text { group }^{\mathrm{a}}\end{array}$ & $\begin{array}{l}\text { Usual } \\
\text { treatment for } \\
\text { both groups }\end{array}$ & & & \\
\hline $\begin{array}{l}\text { Bian } \\
2016 \\
{[35]}\end{array}$ & Outpatient & $<24 h$ & NR & $50 / 50$ & 62 & 73 & SFJD & $\begin{array}{l}\text { Levofloxacin } \\
+ \text { ST }\end{array}$ & No & 7 & $6 ; 7 ; 8$ \\
\hline $\begin{array}{l}\mathrm{Hu} \\
2018 \\
{[36]}\end{array}$ & Inpatient & NR & NR & $60 / 60$ & $63.1 / 63.8$ & $\begin{array}{l}53.3 / \\
52.9\end{array}$ & SFJD & $\begin{array}{l}\text { Antibiotic + } \\
\text { ST }\end{array}$ & No & 10 & $1 ; 3 ; 5 ; 6$ \\
\hline $\begin{array}{l}\text { Huang } \\
2015 \\
{[37]}\end{array}$ & Inpatient & $<48 \mathrm{~h}$ & NR & $45 / 45$ & $66 / 67$ & $\begin{array}{l}66.7 / \\
77.1\end{array}$ & SFJD & $\begin{array}{l}\text { Cefoperazone } \\
\text { and } \\
\text { sulbactam + } \\
\text { ST }\end{array}$ & No & 10 & $1 ; 5 ; 7 ; 9$ \\
\hline $\begin{array}{l}\mathrm{Li} \\
2017 \mathrm{a} \\
{[38]}\end{array}$ & Inpatient & NR & NR & $20 / 20$ & $67.2 / 66.1$ & $\begin{array}{l}80 / \\
80\end{array}$ & SFJD & $\begin{array}{l}\text { Antibiotic + } \\
\text { ST }\end{array}$ & No & 7 & $1 ; 2 ; 9$ \\
\hline $\begin{array}{l}\mathrm{Li} \\
2017 \mathrm{~b} \\
{[39]}\end{array}$ & Inpatient & $<48 h$ & NR & $50 / 50$ & $52.3 / 54.7$ & $\begin{array}{l}74 / \\
70\end{array}$ & SFJD & $\begin{array}{l}\text { Ceftriaxone } \\
\text { (iv.gtt, } 2 \mathrm{~g} / \\
\text { d) }+\mathrm{ST}\end{array}$ & No & 10 & $1 ; 4 ; 7 ; 9$ \\
\hline $\begin{array}{l}\text { Tian } \\
2018 \\
{[40]}\end{array}$ & Inpatient & NR & NR & $43 / 43$ & $61.3 / 60.5$ & $\begin{array}{l}65.1 / \\
60.5\end{array}$ & SFJD & $\begin{array}{l}\beta \text {-lactams + } \\
\text { ST }\end{array}$ & No & 7 & $1 ; 9$ \\
\hline $\begin{array}{l}\text { Wang } \\
2016 \\
{[41]}\end{array}$ & Inpatient & $<48 h$ & NR & $41 / 39$ & $63.5 / 62.5$ & $\begin{array}{l}56.1 / \\
48.7\end{array}$ & SFJD & $\begin{array}{l}\text { Antibiotic + } \\
\text { ST }\end{array}$ & No & 14 & 1 \\
\hline $\begin{array}{l}\text { Wang } \\
2018 \\
{[42]}\end{array}$ & Inpatient & $\leq 48 \mathrm{~h}$ & NR & $35 / 35$ & $54.2 / 52.3$ & $\begin{array}{l}65.7 / \\
71.4\end{array}$ & SFJD & $\begin{array}{l}\text { Antibiotic + } \\
\text { ST }\end{array}$ & No & 10 & $5 ; 6$ \\
\hline $\begin{array}{l}\text { Wei } \\
2019 \\
{[43]}\end{array}$ & Inpatient & NR & NR & $30 / 30$ & $53.3 / 52.7$ & $\begin{array}{l}60 / \\
56.7\end{array}$ & SFJD & $\begin{array}{l}\text { Ceftriaxone } \\
\text { (iv.gtt, } 2 \text { g/ } \\
\text { d) }+\mathrm{ST}\end{array}$ & No & 10(SFJD7) & $1 ; 4 ; 7 ; 9$ \\
\hline $\begin{array}{l}\text { Yao } \\
2017 \\
{[44]}\end{array}$ & Inpatient & NR & NR & $20 / 20$ & $65.4 / 64.1$ & $\begin{array}{l}85 / \\
80\end{array}$ & SFJD & $\begin{array}{l}\text { Antibiotic + } \\
\text { ST }\end{array}$ & No & 7 & $1 ; 2 ; 7 ; 9$ \\
\hline $\begin{array}{l}\text { Zhang } \\
2015 \\
{[45]}\end{array}$ & Inpatient & $<48 \mathrm{~h}$ & NR & $65 / 65$ & $67 / 66$ & $\begin{array}{l}75.4 / \\
72.3\end{array}$ & SFJD & $\begin{array}{l}\text { Cefuroxime + } \\
\text { ST }\end{array}$ & No & 10 & $1 ; 5 ; 9$ \\
\hline $\begin{array}{l}\text { Zhang } \\
2019 \\
{[46]}\end{array}$ & Inpatient & NR & NR & $30 / 30$ & $61.5 / 62.3$ & $\begin{array}{l}76.7 / \\
83.3\end{array}$ & SFJD & $\begin{array}{l}\text { Antibiotic + } \\
\text { ST }\end{array}$ & No & 14 & $1 ; 6 ; 7$ \\
\hline $\begin{array}{l}\text { Zhu } \\
2018 \\
{[47]}\end{array}$ & Inpatient & $<72 \mathrm{~h}$ & NR & $30 / 30$ & NR & $\begin{array}{l}63 / \\
70\end{array}$ & SFJD & $\begin{array}{l}\text { Antibiotic + } \\
\text { ST }\end{array}$ & No & 6 & $1 ; 4 ; 7 ; 9$ \\
\hline
\end{tabular}

Notes: ${ }^{a}$ The dose of SFJD was 4 capsules per time, and 3 times daily in all trials. ${ }^{\text {b }} 1$. treatment failure; 2 . duration of hospital stay; 3 . ICU admission; 4 . time to resolution of clinical symptoms; 5 . PaO2 and $\mathrm{PaCO}$; 6 . lung function (FEV1/FVC ratio); 7. Infection-related index; 8 . health related quality of life; 9 . adverse event. NR not reported, SFJD Shufeng Jiedu capsule, ST symptomatic treatment, iv.gtt intravenous drip

difference in the length of fever (SMD -1.46, - 3.24 to 0.32; $I^{2}=90 \%$; very low certainty) between SFJD group and control group (Additional file 1: Table 4). There was a shorter time to resolution of sputum (two trials, 160 patients, MD -1.68 days; -2.21 to -1.16 days; $I^{2}=0 \%$; low certainty) and crackles (two trials, 160 patients, MD -1.23 days; -2.12 to -0.34 days; $I^{2}=70 \%$; very low certainty) in the SFJD group [39, 43] (Additional file 1: Table 4). In one trial [39] (100 patients), SFJD group showed significantly shorter time to resolution of cough (MD -1.20 days, -1.69 to -0.71 days).

\section{$\mathrm{PaO} 2$ and $\mathrm{PaCO} 2$}

Significant benefits were found for improvement in $\mathrm{PaO} 2$ (4 trials, 390 patients, MD $7.69 \mathrm{mmHg}, 3.68$ to $11.70 \mathrm{mmHg} ; \mathrm{I}^{2}=92 \%$; very low certainty) and reduction in $\mathrm{PaCO} 2$ at end of therapy (4 trials, 390 patients, MD $-3.73 \mathrm{mmHg},-6.01$ to $-1.45 \mathrm{mmHg} I^{2}=69 \%$; very low 
Table 2 Quality assessment: risk of bias

\begin{tabular}{|c|c|c|c|c|c|c|}
\hline \multirow[t]{2}{*}{ Study ID } & \multirow{2}{*}{$\begin{array}{l}\text { Random } \\
\text { sequence } \\
\text { generated }\end{array}$} & \multirow{2}{*}{$\begin{array}{l}\text { Allocation } \\
\text { concealed }\end{array}$} & \multicolumn{2}{|l|}{ Blinding } & \multirow{2}{*}{$\begin{array}{l}\text { Attrition } \\
\text { infrequent }^{\text {a }}\end{array}$} & \multirow{2}{*}{$\begin{array}{l}\text { Free of } \\
\text { selective } \\
\text { reporting }\end{array}$} \\
\hline & & & Patients \& clinicians & Outcome assessors & & \\
\hline Bian 2016 [35] & Probably yes & Probably yes & No & Probably no & Probably no & Probably yes \\
\hline Hu 2018 [36] & Probably yes & Probably yes & No & Probably no & Probably no & Probably yes \\
\hline Huang 2015 [37] & Probably yes & Probably yes & No & Probably no & $N R$ & Probably yes \\
\hline Li 2017a [38] & Probably yes & Probably yes & No & Probably no & $N R$ & Probably yes \\
\hline Li 2017b [39] & Probably yes & Probably yes & No & Probably no & $N R$ & Probably yes \\
\hline Tian 2018 [40] & Yes & Yes & No & Probably no & $N R$ & No \\
\hline Wang 2016 [41] & Yes & Yes & No & Probably no & $N R$ & Probably yes \\
\hline Wang 2018 [42] & Probably yes & Probably yes & No & Probably no & $N R$ & Probably yes \\
\hline Wei 2019 [43] & Probably yes & Probably yes & No & Probably no & $N R$ & Probably yes \\
\hline Yao 2017 [44] & Probably yes & Probably yes & No & Probably no & Probably yes & Probably yes \\
\hline Zhang 2015 [45] & Probably yes & Probably yes & No & Probably no & $N R$ & Probably yes \\
\hline Zhang 2019 [46] & Probably yes & Probably yes & No & Probably no & $N R$ & Probably yes \\
\hline Zhu 2018 [47] & Yes & Yes & No & Probably no & $N R$ & Probably yes \\
\hline
\end{tabular}

Notes: ${ }^{\text {a }}$ Yes defined as less than $10 \%$ attrition to all outcome and those excluded not likely to have made a material difference in outcomes. All answers as: yes, probably yes, probably no, no. NR not reported

certainty) in SFJD group compared to control group (Additional file 1: Table 4).

\section{FEV1/FVC ratio}

Four trials [35, 36, 42, 46] (307 patients) examined the FEV1/FVC ratio. The pooled results demonstrated a significant increase in the FEV1/FVC ratio (MD 4.83, 2.56 to $7.10 ; I^{2}=57 \%$; very low certainty) in the SFJD group.
Subgroup analysis did not have a meaningful impact on the results.

\section{White cell counts and inflammatory markers}

Three trials [43, 44, 47] (159 patients) investigated white blood cell counts in patients at the end of treatment. Pooled results showed that SFJD group had lower white blood cell count $\left(\mathrm{MD}-1.78 \times 10^{9} / \mathrm{L},-3.16\right.$ to $-0.40 \times$

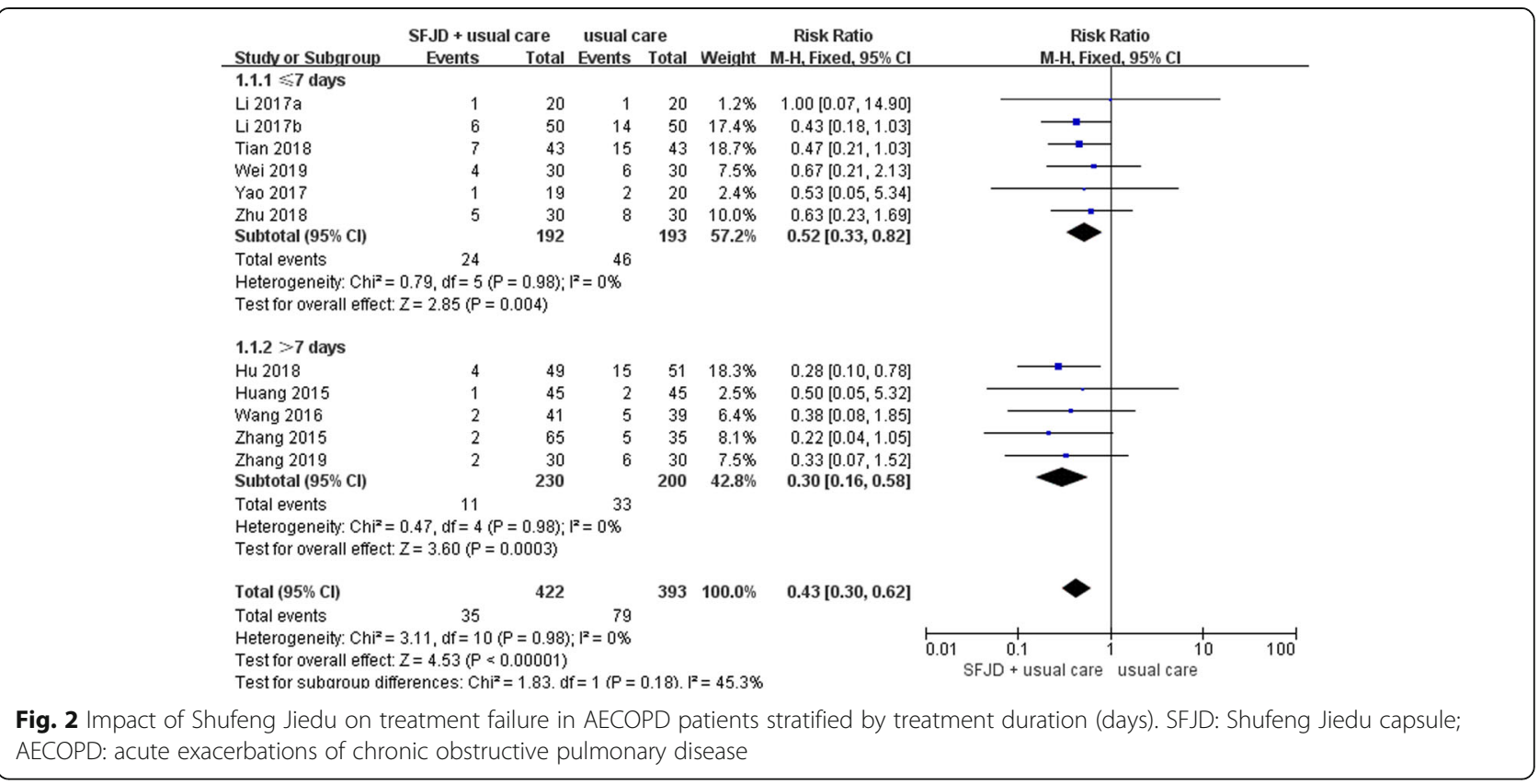


Table 3 Certainty in the estimates rated according to the GRADE. Question: Shufeng Jiedu combine antibiotic and symptomatic treatment versus antibiotic combine symptomatic treatment

\begin{tabular}{|c|c|c|c|c|c|c|c|c|c|c|c|}
\hline \multicolumn{7}{|c|}{ Certainty assessment } & \multicolumn{2}{|c|}{ № of patients } & \multicolumn{2}{|l|}{ Effect } & \multirow[t]{2}{*}{ Certainty } \\
\hline $\begin{array}{l}\text { № of } \\
\text { studies }\end{array}$ & $\begin{array}{l}\text { Study } \\
\text { design }\end{array}$ & $\begin{array}{l}\text { Risk of } \\
\text { bias }\end{array}$ & Inconsistency & Indirectness & Imprecision & $\begin{array}{l}\text { Publication } \\
\text { bias }\end{array}$ & $\begin{array}{l}\text { SFJD + } \\
\text { usual } \\
\text { care }\end{array}$ & $\begin{array}{l}\text { usual } \\
\text { care }\end{array}$ & $\begin{array}{l}\text { Relative } \\
\text { (95\% } \\
\text { Cl) }\end{array}$ & $\begin{array}{l}\text { Absolute } \\
(95 \% \mathrm{Cl})\end{array}$ & \\
\hline
\end{tabular}

\section{Treatment failure}

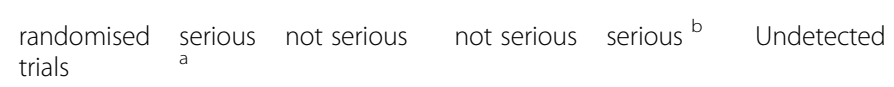

Treatment failure - Treatment duration $>7$ days

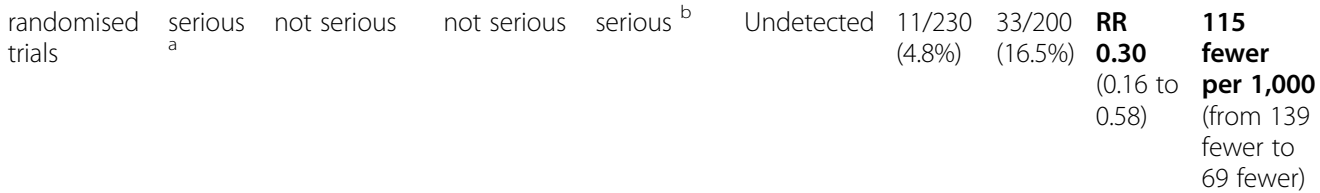

Treatment failure - Mode of administration of antibiotics - iv.gtt randomised serious not serious not serious serious trials

125

fewer

$\oplus \bigoplus O O \quad$ CRITICAL

per 1,000 (from 188 fewer to 0 fewer)

Treatment failure - Mode of administration of antibiotics - Not reported

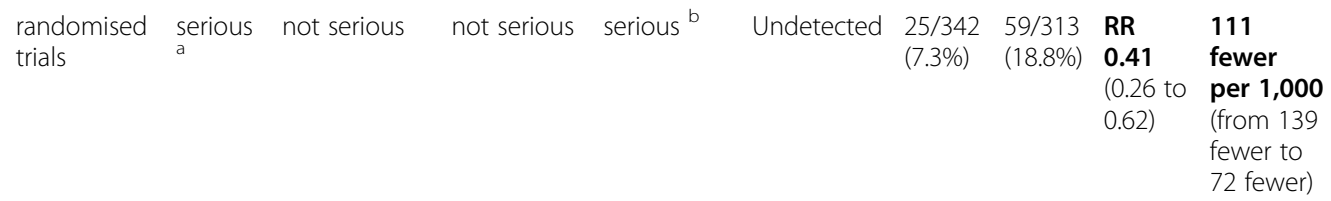

Treatment failure - Complications - Not reported

fewer $\oplus \oplus O O \quad$ CRITICAL LOW

\section{$\bigoplus \oplus O O \quad$ CRITICAL} LOW 
Table 3 Certainty in the estimates rated according to the GRADE. Question: Shufeng Jiedu combine antibiotic and symptomatic treatment versus antibiotic combine symptomatic treatment (Continued)

\begin{tabular}{|c|c|c|c|c|c|c|c|c|c|c|c|}
\hline \multicolumn{7}{|c|}{ Certainty assessment } & \multicolumn{2}{|c|}{ № of patients } & \multicolumn{2}{|l|}{ Effect } & \multirow[t]{2}{*}{ Certainty Importance } \\
\hline $\begin{array}{l}\text { № of } \\
\text { studies }\end{array}$ & $\begin{array}{l}\text { Study } \\
\text { design }\end{array}$ & $\begin{array}{l}\text { Risk of } \\
\text { bias }\end{array}$ & Inconsistency & Indirectness & Imprecision & $\begin{array}{l}\text { Publication } \\
\text { bias }\end{array}$ & $\begin{array}{l}\text { SFJD + } \\
\text { usual } \\
\text { care }\end{array}$ & $\begin{array}{l}\text { usual } \\
\text { care }\end{array}$ & $\begin{array}{l}\text { Relative } \\
(95 \% \\
\mathrm{Cl})\end{array}$ & $\begin{array}{l}\text { Absolute } \\
(95 \% \mathrm{Cl})\end{array}$ & \\
\hline
\end{tabular}

Notes: ${ }^{\mathrm{a}}$ The blinding was not used; ${ }^{\mathrm{b}}$ A small number of events; ${ }^{\mathrm{c}}$ Number of included patients is small. SFJD Shufeng Jiedu capsule, AECOPD acute exacerbations of chronic obstructive pulmonary disease, iv.gtt intravenous drip, $\mathrm{Cl}$ Confidence interval, RR Risk ratio, MD Mean difference

$10^{9} / \mathrm{L} ; I^{2}=79 \%$; very low certainty) (Additional file 1 : Table 4).

Two trials [44, 47] (99 patients) provided information on the proportion of neutrophils at the end of treatment. Meta-analysis showed that patients with AECOPD treated with SFJD had lower proportion of neutrophils (MD -3.69\%, -4.65 to $-2.73 \% ; I^{2}=0 \%$; low certainty) (Additional file 1: Table 4).

Six trials $[35,37,39,43,44,46,47]$ reported on Creactive protein (CRP). Patients treated with SFJD combined with usual care had lower serum CRP levels at end of therapy compared to usual care patients (426 patients, $\mathrm{MD}-5.29 \mathrm{mg} / \mathrm{L},-8.45$ to $-2.14 \mathrm{mg} / \mathrm{L} ; I^{2}=$ 98\%; very low certainty) (Additional file 1: Table 4).

Two trials [39, 43] (160 patients) provided data on procalcitonin among patients. Pooled results showed no significantly difference (MD $-0.61 \mathrm{ng} / \mathrm{L},-1.26$ to 0.04 $\mathrm{ng} / \mathrm{L} ; I^{2}=93 \%$; very low certainty) at the end of treatment in the SFJD group and the usual care group (Additional file 1: Table 4).

\section{Health related quality of life}

Only one trial [35] (77 patients) investigated quality of life. COPD Assessment Test (CAT) score reduced from 21.7 to 15.3 in patients treated with SFJD and from 22.3 to 17.3 in the control group (MD between two groups at the end of treatment $-2.00,-4.30$ to -0.30$)$. Previous study has shown that the minimum clinical important difference is a decrease in CAT score of 2 points [48].

\section{Adverse events}

No difference in the incidence of adverse events was found between those who did and did not take SFJD (8 trials; 605 patients; RR 1.41, 0.46 to $4.33 ; I^{2}=0 \%$; low certainty). Subgroup analyses did not have a meaningful

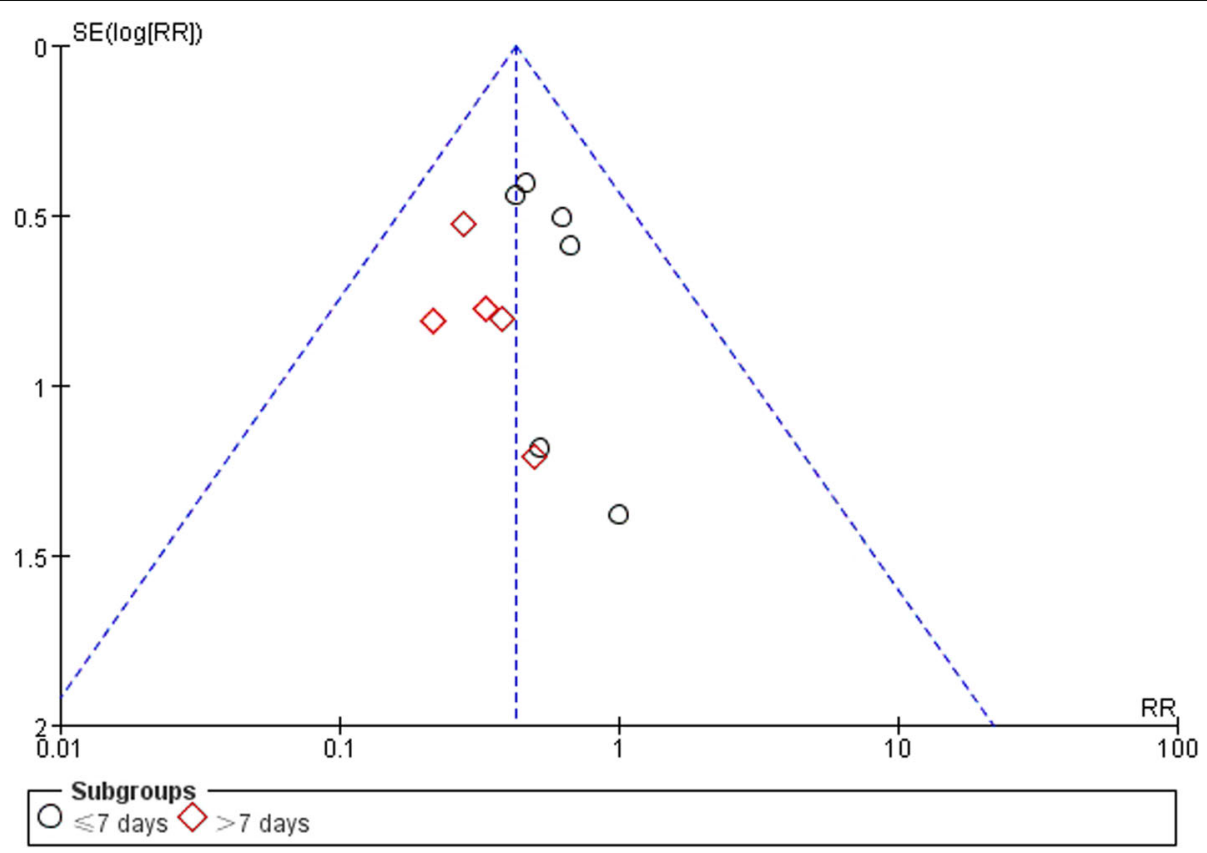

Fig. 3 Funnel plot of treatment failure. SE: Standard error; RR: risk ratio 
impact on the results (Additional file 1: Table 4). The adverse events reported in these trials included transient gastrointestinal tract reactions, including nausea and diarrhoea. No serious adverse event was reported.

\section{Discussion}

\section{Main findings}

Our systematic review found low certainty evidence suggesting possible benefits from SFJD in combination with usual care for patients with AECOPD, compared to usual care. However, these effects can only be reported with low or very low certainty due to high risk of bias, mainly from lack of blinding, and the insufficient number of trials. Our findings suggested a significant reduction in the rate of treatment failure $(57 \%$ reduction in the risk of treatment failure). We found an estimated reduction of 4 days in hospital stay from SFJD with usual care. We also found low certainty evidence that SFJD as adjuvant therapy may offer benefits in physiological outcomes: $\mathrm{PaO} 2, \mathrm{PaCO} 2, \mathrm{FEV} 1 / \mathrm{FVC}$ ratio, white cell counts and inflammatory markers (low to very low certainty). We found no evidence of serious adverse events associated with use of SFJD.

\section{Strengths and limitations}

The review was registered in advance and followed rigorous methodology with pre-specified eligibility criteria, a comprehensive search with English and Chinese databases included without language restrictions, and assessment of eligibility and risk of bias in duplicate. We conducted some pre-defined plausible subgroup and sensitivity analyses and applied GRADE criteria to determine certainty of evidence.

Twelve of the 13 trials we included focused on inpatients, and all trials combined SFJD with antibiotics and symptomatic treatment, which is in line with routine clinical practice. In addition, the daily dosing regimen of SFJD was the same in all trials.

There are several limitations: No trials included placebo. Usual care was not standardised across trials, the characteristics of patients varied and phenotyping was poor so it was difficult to identify a responder population. All trials had high risk of bias in the blinding domain, and most trials had unclear risk of bias in attrition. Additionally, inferences were also limited for some outcomes with a small number of patients and events. Most GRADE evidence certainty was low or very low which suggests that readers should be legitimately concerned with the evidence. However, our findings were robust to a variety of subgroup and sensitivity analyses.

\section{Relation to prior research work}

We identified one published systematic review [49] (in Chinese) of SFJD for AECOPD. This previous systematic review did not register their protocol, and GRADE was not utilised to evaluate the confidence of evidence. The nine trials identified in this previous systematic review were all included in our review. Our results are consistent with the prior systematic review. Inclusion of recent trials allowed us to address additional outcomes, including ICU admission, health related quality of life and time to resolution of clinical symptoms, as well as to provide assessment of included evidence certainty.

\section{Implications}

Our results support the need for a future blinded RCT of SFJD for AECOPD. All trials had a high risk of bias; and as very few trials included outpatients it is unclear whether our findings can be generalised to this setting. Similar effects across outcomes (treatment failure, length of hospital stay, PaO2and PaCO2, FEV1/FVC ratio, clinical symptoms and infection-related index) strengthened the credibility of the findings.

One trial [39] required that participants had to have pulmonary infection confirmed by guidelines for diagnosis and treatment of community-acquired pneumonia [50]. Although subgroup analyses showed that results from this trial were not significantly different from other trials, it remains possible that the effects of SFJD vary by underlying pulmonary infection.

The apparent benefits of SFJD combined with antibiotic and symptomatic treatment in AECOPD are considered important - an absolute reduction in risk of treatment failure (11.8\% lower) and shortening of hospital stay (approximately 4 days fewer) without identifiable long-term or serious adverse events compared to antibiotic and symptomatic treatment.

\section{Conclusion}

Published trials suggested positive effects of SFJD in combination of antibiotics and symptomatic treatments on reducing treatment failure, duration of hospitalisation, symptoms. However, due to the high risk of bias and the limited number of trials, the findings were inconclusive. Further high-quality, rigorously conducted double-blind, placebo-controlled trials are warranted.

\section{Supplementary information}

Supplementary information accompanies this paper at https://doi.org/10. 1186/s12906-020-02924-5.

\footnotetext{
Additional file 1: Table 1. Herbal compositions of Shufeng Jiedu capsule. Table 2. Definitions of treatment failure in 11 trials. Table 3. Subgroup analyses and sensitivity analyses for treatment failure with Shufeng Jiedu for AECOPD patients. Figure 1. Impact of Shufeng Jiedu capsule on treatment failure in AECOPD patients stratified by mode of administration of antibiotics. Figure 2. Impact of Shufeng Jiedu on treatment failure in AECOPD patients stratified by complications. Figure 3. Impact of Shufeng Jiedu on treatment failure in AECOPD patients stratified by clear or unclear randomization concealment. Figure 4.
} 
Impact of Shufeng Jiedu on treatment failure in AECOPD patients stratified by reported loss to follow up or not reported. Figure 5. Impact of Shufeng Jiedu on treatment failure in AECOPD patients used worst plausible assumptions of patients lost to follow up or not used. Figure 6. Impact of Shufeng Jiedu on duration of hospital stay (days) in AECOPD patients. Table 4. Certainty in the estimates rated according to the GRADE.

\section{Abbreviations}

AECOPD: Acute exacerbation of chronic obstructive pulmonary disease; CAT: COPD Assessment Test; Cl: Confidence intervals; CNKI: China National Knowledge Infrastructure; COPD: Chronic obstructive pulmonary disease; FEV1: Forced expiratory volume in $1 \mathrm{~s}$; FVC: Forced vital capacity; GRADE: Grading of Recommendations Assessment, Development and Evaluation; ICU: Intensive care unit; MD: Mean difference; PaCO2: Partial pressure of carbon dioxide; $\mathrm{PaO} 2$ : Partial pressure of oxygen; PRISMA: Preferred Reporting Items for Systematic Reviews and Meta-Analysis; RCTs: Randomised controlled trials; RR: Risk ratio; SFJD: Shufeng Jiedu; SMD: Standard mean difference; VIP: Chinese Scientific Journal Database

\section{Acknowledgements}

Not applicable.

\section{Authors' contributions}

JPL, RYX, YTF had the idea for the study. JPL, RYX, YTF, XYH, MW and MM contributed to study design. RYX, LZW and MKY contributed to acquisition of data. RYX contributed to analysis of data. RX, YF, and JPL drafted the manuscript. LSZ, MYD, GHF, MT, NF, TW revised and commented on the drafted protocol and manuscript. All authors approved the final manuscript.

\section{Funding}

This work was supported by the National Key Research and Development Project (grant no. 2018YFE0102300) and Innovate UK (grant no. 104287610239). Merlin Willcox's salary is funded by NIHR Academic Clinical Lectureship, under grant CL-2016-26-005. The funding sources had no role in the design of the study and collection, analysis, and interpretation of the data and in writing the manuscript.

\section{Availability of data and materials}

All data used in this review are included in this published article.

\section{Ethics approval and consent to participate}

Not applicable.

\section{Consent for publication}

Not applicable.

\section{Competing interests}

The authors declare that they have the following possible conflicts of interest. However, these conflicts of interest did not actually influence the design, analyses, and the reporting of this study in the current article. The Beijing University of Chinese Medicine obtained funding from the Ministry of Science and Technology of the People's Republic of China for a project investigating the use of Chinese herbal medicine for the treatment of chronic obstructive pulmonary disease. The other partners in the project are the University of Southampton, Anhui Jiren Pharmaceutical Co., Ltd. (Jiren is the manufacturer of SFJD), and Phoenix Medical Ltd. The project is part of the "UK-China collaboration to tackle antimicrobial resistance", funded by the UK and Chinese governments. Ru-yu Xia, Yu-tong Fei, Li-shan Zhang, Meng-yuan Dai, Guang-he Fei and Jian-ping Liu received this research funding from Ministry of Science and Technology of the People's Republic of China; Xiao-yang Hu, Merlin Willcox, Mike Thomas, Nick Francis, Tom Wilkinson and Michael Moore received this research funding from Innovate-UK. Jian-ping Liu is a member of the editorial board (Section Editor) of BMC Complementary Medicine and Therapies.

\section{Author details}

${ }^{1}$ Centre for Evidence-Based Chinese Medicine, Beijing University of Chinese Medicine, No. 11 North Sanhuan East Road, Chaoyang District, Beijing 100029, China. ${ }^{2}$ School of Primary Care, Population Sciences and Medical
Education, University of Southampton, Aldermoor Health Centre, Aldermoor Close, Southampton SO16 5ST, UK. ${ }^{3}$ Respiratory Department, Dongzhimen Hospital Affiliated to Beijing University of Chinese Medicine, No.5 Hai Yun Cang, Dongcheng District, Beijing 100700, China. ${ }^{4}$ Department of Respiratory and Critical Care Medicine, First Affiliated Hospital of Anhui Medical University, No.210 Jixi Road, shushan District, Hefei 230022, Anhui Province, China. ${ }^{5}$ Clinical and Experimental Sciences, Faculty of Medicine, University of Southampton, Southampton General Hospital, Tremona Road, Southampton SO16 6YD, UK. ${ }^{6}$ Institute of Integrated Traditional Chinese Medicine and Western Medicine, Guangzhou Medical University, Guangzhou 510120, China.

Received: 4 September 2019 Accepted: 14 April 2020

Published online: 24 May 2020

\section{References}

1. GBD 2017 DALYs and HALE Collaborators. Global, regional, and national disability-adjusted life-years (DALYS) for 359 diseases and injuries and healthy life expectancy (HALE) for 195 countries and territories, 1990-2017: a systematic analysis for the Global Burden of Disease Study 2017. Lancet. 2018:392:1859-922.

2. Wang $C, X u$ JY, Yang $L, X u$ YJ, Zhang $X Y$, Bai $C X$, et al. Prevalence and risk factors of chronic obstructive pulmonary disease in China (the China pulmonary health $[\mathrm{CPH}]$ study): a national cross-sectional study. Lancet. 2018:391:1706-17.

3. Snell N, Strachan D, Hubbard R, Gibson J, Gruffydd-Jones K, Jarrold I. S32 epidemiology of chronic obstructive pulmonary disease (COPD) in the Uk: findings from the british lung foundation's 'respiratory health of the nation' project. Thorax. 2016;71(Suppl 3):A20.1-A20.

4. NHS Medical Directorate. COPD Commissioning Toolkit. London: Department of Health; 2012

5. Hurst JR, Wedzicha JA. What is (and what is not) a COPD exacerbation: thoughts from the new GOLD guidelines. Thorax. 2007;62:198-9.

6. Wedzicha JA, Seemungal TA. COPD exacerbations: defining their cause and prevention. Lancet. 2007;370:786-96.

7. Seemungal TA, Donaldson GC, Paul EA, Bestall JC, Jeffries DJ, Wedzicha JA. Effect of exacerbation on quality of life in patients with chronic obstructive pulmonary disease. Am J Respir Crit Care Med. 1998;157:1418-22.

8. Burge S, Wedzicha JA. COPD exacerbations: definitions and classifications. Eur Respir J. 2003:21(Suppl 41):46s-53s.

9. Singh D, Agusti A, Anzueto A, Barnes PJ, Bourbeau J, Celli BR, et al. Global strategy for diagnosis, management and prevention of chronic obstructive lung disease: the GOLD science committee report 2019. Eur Respir J. 2019; 53:1900164.

10. Acute exacerbation of chronic obstructive pulmonary disease (AECOPD) panel. Expert consensus on diagnosis and treatment of acute exacerbation of chronic obstructive pulmonary disease (AECOPD) in China (2017 updated). Int J Respir. 2017;37:1041-57.

11. Celli BR, Barnes PJ. Exacerbations of chronic obstructive pulmonary disease. Eur Respir J. 2007;29:1224-38.

12. Soler-Cataluña JJ, Martínez-García MA, Sánchez PR, Sakedo E, Navarro M Ochando R. Severe acute exacerbations and mortality in patients with chronic obstructive pulmonary disease. Thorax. 2005;60:925-31.

13. Sullivan SD, Ramsey SD, Lee TA. The economic burden of COPD. Chest. 2000:117:5s-9s.

14. Schermer T, Chavannes N, Saris C, Akkermans R, van Schayck C, van Weel C. Exacerbations and associated health care cost in patients with chronic obstructive pulmonary disease in general practice. Results from the COOPT trial. Eur Respir J. 2002;20(Suppl 38):398s.

15. Wedzicha JA, Miravitlles M, Hurst JR, Calverley PMA, Albert RK, Anzueto A, et al. Management of COPD exacerbations: a European Respiratory Society/ American Thoracic Society guideline. Eur Respir J. 2017:49:1600791.

16. McCrory DC, Brown CD. Anticholinergic bronchodilators versus beta2sympathomimetic agents for acute exacerbations of chronic obstructive pulmonary disease. Cochrane Database Syst Rev. 2002;4:CD003900.

17. Vollenweider DJ, Frei A, Steurer-Stey CA, Garcia-Aymerich J, Puhan MA. Antibiotics for exacerbations of chronic obstructive pulmonary disease. Cochrane Database Syst Rev. 2018:10:CD010257.

18. Walters JAE, Tan DJ, White CJ, Gibson PG, Wood-Baker R, Walters EH. Systemic corticosteroids for acute exacerbations of chronic obstructive pulmonary disease. Cochrane Database Syst Rev. 2014;9:CD001288. 
19. Chen HY, Ma CH, Cao KJ, Chung-Man Ho J, Ziea E, Wong VT, et al. A systematic review and meta-analysis of herbal medicine on chronic obstructive pulmonary diseases. Evid Based Complement Alternat Med. 2014;2014:925069.

20. Gao Z, Li FS, Xu D, Jing J, Upur H. Meta-analysis of clinical effect of Xiaoginglong decoction on acute exacerbation of chronic obstructive pulmonary disease (2016 update version). China J Tradit Chin Med Pharm. 2017;32:721-30.

21. Li JS, Wang ZW, Yu XQ, Wang MH, Li SY. Systematic review of traditional Chinese medicine for acute exacerbation of chronic obstructive pulmonary disease. Tianjin J Tradit Chin Med. 2008;25:428-32.

22. $\mathrm{Li} \mathrm{YH}$, Zhu HJ. Systematic assessment on randomized controlled trials for treatment of acute exacerbation of chronic obstructive pulmonary disease by tanreqing injection. Pract Pharm Clin Remedies. 2011;14:281-5.

23. Ren X, Guan J, Zhang ZH, Cheng FJ, Wang SS, Wang S, Ma CY. Meta-analysis of curative effect of Asarone injection on the treatment of chronic obstructive pulmonary disease with acute exacerbation. Yunnan J Tradit Chin Med Mater Med. 2016;37:22-6.

24. Chen $\mathrm{H}, \mathrm{Xu} \mathrm{GL}$. Meta-analysis of clinical effect of Xiaoqinglong Decoction on acute exacerbation of chronic obstructive pulmonary disease. Hunan J Tradit Chin Med. 2016;32:141-143+173.

25. Meng YF. Systematic review of randomized control trials on traditional Chinese medicine dialectical therapy for acute exacerbation of chronic obstructive pulmonary disease. Beijing: Beijing University of Chinese Medicine; 2017.

26. Wu M. Meta-analysis on efficacy of Jiajian qingjin huatan decoction in treatment of phlegm heat resistance AECOPD. Guangxi: Guangxi University of Chinese Medicine; 2016

27. Moher D, Liberati A, Tetzlaff J, Altman DG, the PRISMA group. Preferred Reporting Items for Systematic Reviews and Meta-Analyses: The PRISMA Statement. PLoS Med. 2009;6:e1000097.

28. Xia RY, Hu XY, Fei YT, Willcox M, Wen LZ, Yu MK, et al. Shufeng Jiedu capsule for acute exacerbation of chronic obstructive pulmonary disease: a systematic review and meta-analysis. PROSPERO 2019:CRD42019133682. http://www.crd.york.ac.uk/PROSPERO/display_record.asp?ID=CRD420191336 82. Assessed 3 Sept 2019.

29. Higgins JP, Green S. Cochrane handbook for systematic reviews of interventions:. Version 5.1.0[updated march 2011]: The Cochrane Collaboration; 2011. http://handbook-5-1.cochrane.org/. Assessed 3 Sept 2019.

30. Guyatt GH, Busse J. Methods Commentary: Risk of Bias in Randomized Trials 1. http://distillercer.com/resources/methodological-resources/risk-of-biascommentary/.Assessed 3 Sept 2019.

31. Guyatt $G H$, Oxman $A D$, Vist GE, Kunz R, Schünemann HJ. GRADE: an emerging consensus on rating quality of evidence and strength of recommendations. BMJ. 2008:336:924-6.

32. Landis JR, Koch GG. The measurement of observer agreement for categorical data. Biometrics. 1977;33:159-74.

33. Higgins JPT, Thompson SG. Quantifying heterogeneity in a meta-analysis. Stat Med. 2002;21:1539-58.

34. Akl EA, Briel M, You JJ, Sun X, Johnston BC, Busse JW, et al. Potential impact on estimated treatment effects of information lost to follow-up in randomised controlled trials (LOST-IT): systematic review. BMJ. 2012;344: e2809.

35. Bian W, Lu LW. Clinical observation of Shufeng Jiedu capsule in treatment of acute exacerbation of chronic obstructive pulmonary disease. J Emerg Tradit Chin Med. 2016;25:2182-4.

36. Hu HZ, Xiong L, Yang SC, Yang RX. Effect of Shufeng Jiedu capsule as adjuvant therapy for acute exacerbation of chronic obstructive pulmonary disease. J Pract Tradit Chin Medi. 2018;34:961-2.

37. Huang J, Liu JC. Clinical curative effect observation of Shufengjiedu capsule in treating acute exacerbations of chronic obstructive pulmonary disease. World J IntegrTradit West Med. 2015;10:810-1 815.

38. Li J, Yang J, Zhao L. Curative effect evaluation of Shufeng Jiedu capsules on acute exacerbation of chronic obstructive pulmonary disease. China J Tradit Chin Med Pharm. 2017;32:5243-5

39. Li X. Clinical observation of Shufeng Jiedu capsule in the treatment of acute exacerbation of chronic obstructive pulmonary disease with pulmonary infection. China J Tradit Chin Med Pharm. 2017;32:395-7.

40. Tian TL, Rong L, Qu XK, Zhao X, Zhang HB, Xia J. Effect of Shufeng Jiedu capsule on inflammatory regulation in acute exacerbation of chronic obstructive pulmonary disease. J Emerg Tradit Chin Med. 2018;27:1814-6.
41. Wang FH, Lin SN, Wu DH, He HW, Shi HH. Influence of Shufeng Jiedu capsule on IL-8 and TNF-a of patients with acute exacerbation of chronic obstructive pulmonary disease. J Emerg Tradit Chin Med. 2016;25:2171-3.

42. Wang $\mathrm{CH}$, Wang MY. Effect of Shufeng Jiedu capsule combined with western medicine in the pulmonary function of AECOPD patients. Drug Eval Res. 2018;41:1867-70.

43. Wei Y, Li XY, Luo J. Evaluation of Shufeng Jiedu capsule in the treatment of acute exacerbation of chronic obstructive pulmonary disease. J Emerg Tradit Chin Med. 2019;28:320-2.

44. Yao X, Cao LF, Yang J, Yao MX, Zhao L. Shufeng Jiedu capsule for acute exacerbation of chronic obstructive pulmonary disease curative effect evaluation of Shufeng Jiedu capsules for the treatment of acute exacerbation of chronic obstructive pulmonary disease. China J Tradit Chin Med Pharm. 2017;32:347-50.

45. Zhang LG, Li Y. Study on Shufeng Jiedu capsules for acute exacerbation of chronic obstructive pulmonary disease and its affect on patients' status of nutrition. Beijing Med J. 2015;37:974-6.

46. Zhang JY, Xu S. Shufeng Jiedu capsule for acute exacerbation of chronic obstructive pulmonary disease effect of Shufeng Jiedu capsule on acute exacerbation of chronic obstructive pulmonary disease. J Emerg Tradit Chin Med. 2019;28:505-7.

47. Zhu CD, Deng X, Wang S. Clinical observation on Shufeng Jiedu capsule combined with western medicine basic plan in treating acute exacerbations of chronic obstructive pulmonary disease with syndrome of wind-heat invading lung. China J Tradit Chin Med Pharm. 2018;33:4227-30.

48. Kon SSC, Canavan JL, Jones SE, Nolan CM, Clark AL, Dickson MJ, et al. Minimum clinically important difference for the COPD assessment test: a prospective analysis. Lancet Respir Med 2014, 2(3):195-203.

49. Zhang K, Wang LY, Li XL, Wang HF, Yu XQ. Meta-analysis of efficacy and safety of Shufeng Jiedu capsule for acute exacerbation of chronic obstructive pulmonary disease. Guangming J Chin Med. 2006:32:35-9.

50. Respiratory Society, Chinese Medical Association. Guidelines for diagnosis and treatment of community-acquired pneumonia. Chin Pract J Rural. 2013; 20:11-5.

\section{Publisher's Note}

Springer Nature remains neutral with regard to jurisdictional claims in published maps and institutional affiliations.

Ready to submit your research? Choose BMC and benefit from:

- fast, convenient online submission

- thorough peer review by experienced researchers in your field

- rapid publication on acceptance

- support for research data, including large and complex data types

- gold Open Access which fosters wider collaboration and increased citations

- maximum visibility for your research: over $100 \mathrm{M}$ website views per year

At $\mathrm{BMC}$, research is always in progress.

Learn more biomedcentral.com/submissions 